\title{
Avaliação da pigmentação de sulcos e fissuras em primeiros molares permanentes
}

Evaluation of pigmentation of grooves and fissures in first permanent molars

Evaluación de la pigmentación de suelos y fisuras en primeros molares permanentes

\section{Karine TAKAHASHI ${ }^{1}$}

Letícia Facholi AFANACI ${ }^{2}$

Monisse Avelino da SILVA2

Raphael Fernando Barion FERRARESSE ${ }^{2}$ Heitor Ceolin ARAUJO ${ }^{3}$

Sueli Cristina Schadek ZAGO

${ }^{I}$ Docente, Curso de Odontologia, Universidade do Oeste Paulista Presidente UNOESTE, 19050-920 Prudente-SP, Brasil

${ }^{2}$ Graduação em Odontologia, Universidade do Oeste Paulista Presidente UNOESTE, 19050-920 Prudente-SP, Brasil

${ }^{3}$ Doutorando, Programa de Pós-Graduação em Ciência Odontológica, UNESP - Univ. Estadual Paulista, 16015-050 Araçatuba-SP, Brasil

\section{Resumo}

Introdução: A cárie dentária ainda é considerada um problema de Saúde Pública. O período de irrompimento dentário é considerado fator de risco. Existem dificuldades no diagnóstico e manejo das lesões incipientes em dentes permanentes. Objetivo: Este estudo teve por objetivo avaliar a pigmentação de sulcos e fissuras em primeiros molares permanentes. Material e Método: A pesquisa foi submetida ao Comitê de Ética em Pesquisa e aprovada pelo protocolo 3501. Foram incluídas crianças entre 6 a 12 anos de idade de ambos os gêneros de escolas municipais e escola particular. Foram avaliados primeiros molares permanentes em pacientes de alto e médio risco a cárie dentária. Amostras de biofilme foram obtidas e a presença de bactérias foi determinada por cultura. Resultados: As bactérias mais comumente encontradas foram S. pyogenes, $S$. mitis e $S$. salivarius. Os dentes inferiores 36 e 46 foram os mais afetados e, quando comparados aos dentes superiores, houve diferença estatística $(\mathrm{p}<0,05)$. Conclusão: A colonização bacteriana e a experiência de cárie podem ser afetadas pela idade, morfologia dentária e outros fatores.

Descritores: Dentição Permanente; Fissuras Dentárias; Microbiologia; Placa Dentária; Streptococcus pyogenes.

\section{Abstract}

Introduction: Dental caries still considered as a public health problem. The eruption period is considered a risk factor. There are difficulties in the diagnosis and management of incipient caries in permanent teeth. Objective: This study aimed to evaluate the pigmentation of grooves and fissures in first permanent molars. The research was submitted to the Research Ethics Committee and approved by protocol 3501 . Material and Methods: Were included children of both genders of the municipal schools and private school. First permanent molars were evaluated in high and medium risk patients. Biofilm samples were obtained from the groove and pigmented fissures region and the presence of bacteria was determined by culture. Results: The most commonly found bacteria were S. pyogenes, S. mitis and $S$. salivarius. The lower teeth 36 and 46 were the most affected and when compared to the upper teeth, there was a statistical difference $(\mathrm{p}<0.05)$. Conclusion: Since bacterial colonization and caries experience may be affected by age, dental morphology and other contradictory factors.

Descriptors: Dentition, Permanent; Dental Fissures; Microbiology; Dental Plaque; Streptococcus pyogenes.

\section{Resumen}

Introducción: La caries dental sigue siendo considerada un problema de salud pública. El período de irrompaje dental se considera un factor de riesgo. Existen dificultades en el diagnóstico y manejo de las lesiones incipientes en dientes permanentes. Meta: Este estudio tuvo por objetivo evaluar la pigmentación de surcos y fisuras en primeros molares permanentes. La investigación fue sometida al Comité de Ética en Investigación y aprobada por el protocolo 3501. Material y método: Fueron incluidos niños entre 6 a 12 años de ambos géneros de escuelas municipales y escuela particular. Se evaluaron primeros molares permanentes en pacientes de alto y medio riesgo a la caries dental. Las muestras de biofilm fueron obtenidas y la presencia de bacterias fue determinada por cultivo. Resultados: Las bacterias más comúnmente encontradas fueron S. pyogenes, S. mitis y S. salivarius. los dientes inferiores 36 y 46 fueron los más afectados y, cuando comparados a los dientes superiores, hubo diferencia estadística $(\mathrm{p}<0,05)$. Conclusión: Una vez que la colonización bacteriana y la experiencia de caries pueden verse afectados por la edad, la morfología dental y otros factores.

Descriptores: Dentición Permanente; Fisuras Dentales; Microbiología; Placa Dental; Streptococcus pyogenes.

\section{INTRODUÇÃO}

A cárie dentária, mesmo com os avanços na Odontologia, ainda é considerada um problema de Saúde Pública. Os molares permanentes tendem a ser dentes com maior ocorrência de cárie dentária pela facilidade de acúmulo de biofilme em sulcos e fissuras. Crianças brasileiras de 12 anos de idade apresentam, em média, 2,07 dentes com experiência de cárie ${ }^{1}$.

A cárie dentária é considerada uma doença multifatorial, onde consideramos que o açúcar é um fator essencial para sua ocorrência, e outros fatores como aspecto do dente e bactéria, são adicionais ao açúcar e não alternativas para ele ${ }^{2}$. Ainda assim, é frequentemente chamada de uma condição multifatorial pelo fato de o processo da doença envolver também outros carboidratos, microrganismos orais, ácidos, diferentes propriedades de diferentes dentes, fluxo salivar, o papel de fluoretos, e, modificando a velocidade da condição, a frequência de consumo de carboidratos específicos ${ }^{3}$.

Sempre que o ácido produzido pela bactéria é neutralizado pela saliva, a desmineralização e remineralização podem compensar uma à outra. Entretanto, com o aumento do consumo de carboidratos fermentáveis, a produção de ácido é mais intensa e os eventos de desmineralização podem, não mais, serem compensados pela remineralização ${ }^{4}$.

Dentes parcialmente irrompidos demonstram significativamente maior tendência ao acúmulo de biofilme. O padrão de distribuição de lesões de cárie ativas tende a acompanhar o padrão de acúmulo de biofilme ${ }^{5}$. Estudos tem mostrado que é alta a incidência de cárie oclusal nos primeiros molares permanentes durante o processo de irrompimento, imediatamente após o irrompimento e depois de três anos de irrompimento ${ }^{6}$. A natureza multifatorial da cárie dentária e os aspectos comportamentais 
associados a ela sugerem que há uma susceptibilidade envolvida no processo 5 .

O período de irrompimento dentário é considerado fator de risco para o desenvolvimento de cárie, pois as superfícies oclusais oferecem boas condições de acúmulo de placa bacteriana e desenvolver mais cárie neste período devido a função oral mecânica. O maior desafio no manejo do processo carioso é controlar o progresso da cárie principalmente por tratamentos não operatórios e pela limitação do número de uma população sujeita a tratamentos operatórios ${ }^{7}$. O diagnóstico de cárie oclusal torna-se um desafio para clínicos e epidemiologistas, relacionando a dificuldade de se diagnosticar pelo exame visual tátil lesões iniciais ${ }^{8}$.

É importante avaliar que a presença de biofilme dental em si não necessariamente resulta no desenvolvimento, que pode ser identificada tanto clinicamente quanto radiograficamente ${ }^{9}$.

Diferentes critérios de diagnóstico para detecção de lesões de cárie dentária têm sido propostos para aumentar a precisão e reprodutibilidade do exame clínico. O sistema de detecção de lesões cariosas (ICDAS), classifica as superfícies dentárias cariadas em 7 códigos, que variam de 0 a $6^{10}$. Um objetivo importante no desenvolvimento do ICDAS é fornecer flexibilidade para clínicos e pesquisadores para escolher o estágio do processo carioso e outras características que atendam às necessidades de suas pesquisas $\mathrm{e}$ práticas $^{11}$.

Apesar do declínio da cárie dentária nas últimas décadas, devido a utilização de produtos fluoretados e evolução de medidas preventivas pelo aumento das pesquisas científicas neste campo, ainda existem dificuldades no diagnóstico e manejo das lesões iniciais ${ }^{12}$.

Em crianças que tem alto risco a cárie, a aplicação de selantes nas superfícies oclusais dos primeiros molares após seu irrompimento, poderia reduzir a probabilidade do desenvolvimento de cárie nessas superfícies. Além disso, selando poderia reduzir a experiência de cárie nas crianças e atrasar o processo carioso na dentição permanente ${ }^{13}$.

Estudos mostraram que os colonizadores de superfícies recentemente limpas constituem uma parte seleta de microflora oral, principalmente $S$. sanguinis, S. oralis, S. mitis ${ }^{14}$. Streptococcus mutans e Streptococcus sobrinus são considerados como sendo os principais agentes etiológicos da cárie dentária ${ }^{15}$. Streptococcus mutans tem mostrado ser mais prevalente do que Streptococcus sobrinus em amostras de placa dental ${ }^{16,17}$ enquanto vários estudos epidemiológicos mostram que a prevalência de Streptococcus sobrinus é mais associada a alta atividade de cárie ${ }^{18,19}$. Alguns estudos longitudinais mostram que há relação entre essas duas espécies e a atividade de cárie em crianças ${ }^{19,20}$.
Existem dificuldades no diagnóstico e manejo de lesões de cárie incipientes em dentes permanentes, apesar de serem comuns no dia-a-dia da prática clínica. Estudos avaliando estes aspectos devem ser estimulados, principalmente quando se busca envolvimento clínico. Este estudo teve por objetivo avaliar a pigmentação de sulcos e fissuras em primeiros molares permanentes.

\section{MATERIAL E MÉTODO}

\section{Aprovação do projeto de pesquisa}

Previamente à realização deste estudo, o projeto foi submetido ao Comitê de Ética em Pesquisa da Universidade do Oeste Paulista, UNOESTE, sendo aprovado pelo protocolo 3501. A fase experimental foi realizada a partir da sua aprovação e obtenção do consentimento livre e esclarecido dos responsáveis pelos participantes da pesquisa e pelo consentimento livre da criança.

\section{Delineamento experimental}

A presente pesquisa se tratou de uma análise que avaliou aspectos clínicos e microbiológicos da pigmentação de sulcos e fissuras em primeiros molares permanentes com retornos de 6 meses após identificação inicial. Participaram da mesma, 104 crianças na faixa etária de 6 a 12 anos, matriculadas nas escolas E.M Prof ${ }^{a}$ Zenóbia Gregório Campelo Cabral do município de Mirante do Paranapanema, Colégio Atlas LTDA. do município de Santo Anastácio e E.M Odette Duarte da Costa do município de Presidente Prudente, com primeiros molares permanentes já irrompidos. Nestas escolas foram apresentados dois vídeos educativos de higiene oral, assim como atividades educativas para reforço motivacional de higiene bucal das crianças.

\section{Critérios de inclusão}

Foram incluídas no presente estudo crianças com alto e médio risco a cárie dentária, cujos primeiros molares permanentes, com sulcos e fissuras pigmentados em superfícies oclusal, se mostrassem completamente irrompidos desde o início da pesquisa.

\section{Critérios de exclusão}

Tendo em vista o exame clínico inicial, foram excluídos do presente estudo as crianças que apresentassem lesão cariosa com cavitação em qualquer superfície do dente avaliado, selante ou restauração na mesma superfície da pigmentação, pigmentação dos sulcos e fissuras associada ao uso de produtos odontológicos, cavitação em esmalte sem dentina aparente (ICDAS 3), além dos pacientes que, por livre e espontânea vontade, não se mostraram dispostos a participar da pesquisa.

De cada criança selecionada do grupo experimental para a pesquisa, realizou-se o preenchimento de uma ficha ${ }^{21}$. A primeira fase da pesquisa constou da obtenção dos espécimes clínicos com a coleta de biofilme dos sulcos e fissuras 
pigmentadas dos primeiros molares permanentes. Além da fase de coleta, realizou-se o exame clínico, visual e tátil, das mesmas, a fim de se registrar as características clínicas da pigmentação, como: dente pigmentado, superfície dentária acometida, distribuição, cor, textura, cavitação. No total, foram obtidos 174 dentes com sulcos e fissuras pigmentadas.

\section{- Coleta de dados}

Constou de duas etapas, uma clínica e outra laboratorial. Para o exame clínico, após a coleta das amostras clínicas, os pacientes que foram selecionados receberam uma profilaxia prévia com pedra pomes e água, dispondo de uma escova de Robinson conectada em motor de baixa rotação e contra-ângulo para retirada do biofilme da superfície dentária pigmentada a ser avaliada. Foi efetuado o exame clínico visual e tátil, com iluminação artificial do campo operatório, espelho clínico e uma sonda OMS, por examinadores previamente calibrados, do dente que apresentou a pigmentação. A sonda percorreu os sulcos e fissuras pigmentadas em um único sentido, apenas uma vez e sem pressão, com o objetivo de verificar cavitações na superfície dentária e evitar danos estruturais à mesma.

Durante o exame clínico das crianças, foram observadas as características clínicas mais comuns dos dentes permanentes com sulcos e fissuras pigmentadas: superfície acometida, distribuição (parcial ou pontos separados), cor (marrom ou preto), textura (dura ou amolecida), cavitação (ausente ou presente).

As crianças que possuíam os primeiros molares permanentes com pigmentação nos sulcos e fissuras foram anotadas em ficha. Em seguida, registrados os seguintes dados: data do primeiro diagnóstico do dente com sulcos e fissuras pigmentados; data do primeiro exame clínico; o dente pigmentado; a superfície dentária acometida; a distribuição da pigmentação (parcial ou pontos separados); a cor (marrom ou preto); a textura (dura ou amolecida); a cavitação (presente ou ausente);

$\mathrm{O}$ índice ICDAS (International Caries Detection and Assessment System) indica detecção da cárie a partir de etapas do processo carioso, topografia (a partir de superficies lisas e fissuras), anatomia dental (coroas e raízes) e restauração. Indica, também, avaliação do processo carioso pela cavitação e atividade (Quadro 1). Há dois tipos de validação do ICDAS. O primeiro é baseado na avaliação qualitativa de critérios que mensuram o processo carioso. Outro meio de validação é baseado na correlação quantitativa entre a avaliação clínica de superfícies histológicas no dente ou desmineralização de esmalte ou dentina.

Para obtenção dos espécimes clínicos e processamento laboratorial procedeu-se ao preparo do meio de cultura com 90,07 gramas de pó para 500 ml de água destilada. Em seguida, a mistura foi colocada num balão de fundo chato e fechada. Foi levada à autoclave por 30 minutos até atingir $121^{\circ} \mathrm{C}$, depois de atingir essa temperatura, esperou-se 15 minutos, até que a temperatura fosse reduzida para poder ser retirado com segurança. Após retirar da autoclave, com a bancada desinfetada com álcool 70, as placas de Petri foram dispostas na mesma e o meio de cultura foi despejado. Após esse procedimento, cada placa foi fixada a partir da chama do bico de Bunsen para impedir contaminação secundária e colocada na estufa envolta com filme plástico de PVC por 24 horas. As placas foram retiradas da estufa e levada ao local de coleta permanecendo em temperatura adequada e durante a coleta, cada placa foi aberta próxima ao fogo para evitar contaminação. Os espécimes clínicos do biofilme microbiano presentes no interior de sulcos e fissuras pigmentados foram coletados com auxílio de microbrushs extrafinos (KG SORENSEN ${ }^{\circledR}$ Indústria e Comércio Ltda - Cotia, São Paulo, Brasil) estéreis que foram delicadamente friccionados na superfície pigmentada por 30 segundos. As amostras obtidas foram colocadas em placas de Petri contendo meio de cultura MSB (Mitis Salivarius Bacitracina - Sigma Aldrich $^{\circledR}$ ), em seguida as placas foram colocadas na estufa por 48 horas e posterior análise para observar o crescimento das mesmas e para a determinação de contagem de colônias isoladas.

\section{RESULTADOS}

- Dados gerais do grupo amostral

A amostra foi composta por 104 pacientes, sendo $61(58,6 \%)$ do gênero feminino e $43(41,4 \%)$ do gênero masculino. A distribuição dos integrantes do grupo experimental de acordo com a idade variou de 6 a 12 anos, com média de 14,85 e mediana de 9 anos.

\section{- Perfil clínico da pigmentação dentária dos sulcos e fissuras}

Os dados a seguir se referem às características clínicas da pigmentação dos sulcos e fissuras em primeiros molares permanentes, divididas em: dente acometido; superfície dentária acometida; distribuição na superfície; cor; cavitação; textura; dente acometido. A Figura 1 mostra a distribuição do número e porcentagem dos dentes acometidos pela pigmentação de sulcos e fissuras

Observa-se que os dentes 36 e 46 foram os que mais apresentaram pigmentação, com o dente 36 com maior acometimento na escola municipal E.M Odette Duarte da Costa $(38,1 \%)$ e dente 46 com maior acometimento na escola municipal E.M Prof ${ }^{a}$ Zenóbia Gregório Campelo Cabral (39,7\%), não apresentando diferença estatística entre eles, porém quando comparado aos superiores, há uma diferença estatística $(\mathrm{p}<0,05)$, sendo utilizado o teste de Fischer para análise das variáveis. 


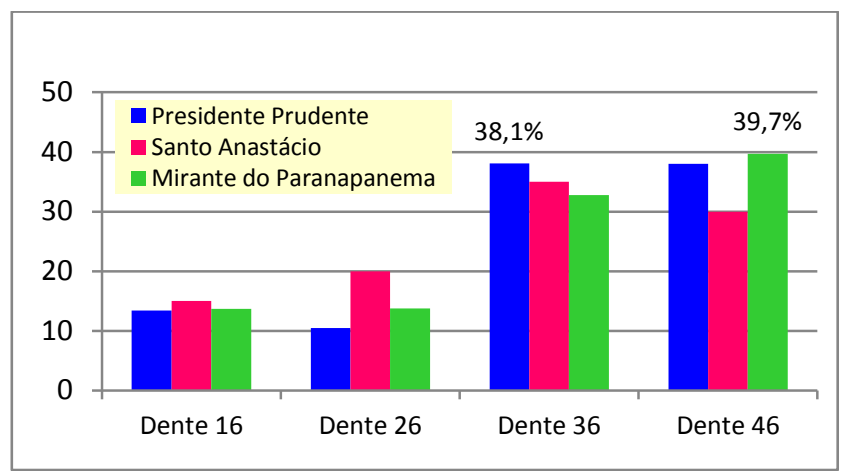

Figura 1: Distribuição percentual dos dentes acometidos.

A Figura 2 apresenta a distribuição do número e porcentagem de um agrupamento feito dos dentes acometidos de acordo com arcadas superior e inferior. Desse modo, observou-se que 150 dentes $(86,2 \%)$ se localizavam no arco inferior e que 55 $(31,6 \%)$ localizavam-se no arco superior.

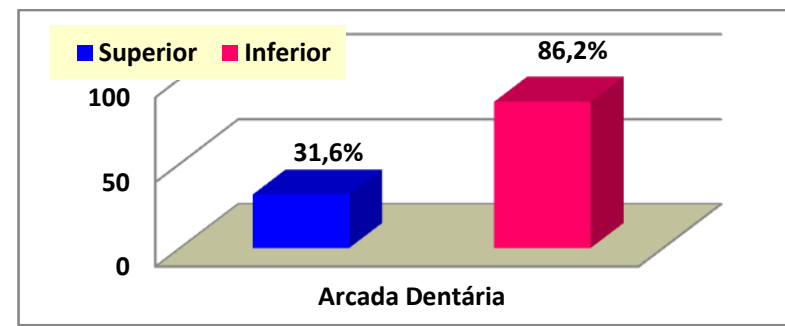

Figura 2: Distribuição percentual dos dentes acometidos de acordo com a arcada dentária.

\section{- Superfície dentária acometida}

A Figura 3 mostra a distribuição do número e porcentagem de acordo com a superfície dentária acometida pela pigmentação de sulcos e fissuras. Notou-se que a superfície mais acometida foi a oclusal (média de $71,1 \%$ ), seguida de palatina (média de $14,9 \%$ ) e por último a vestibular (média de $10 \%$ ).

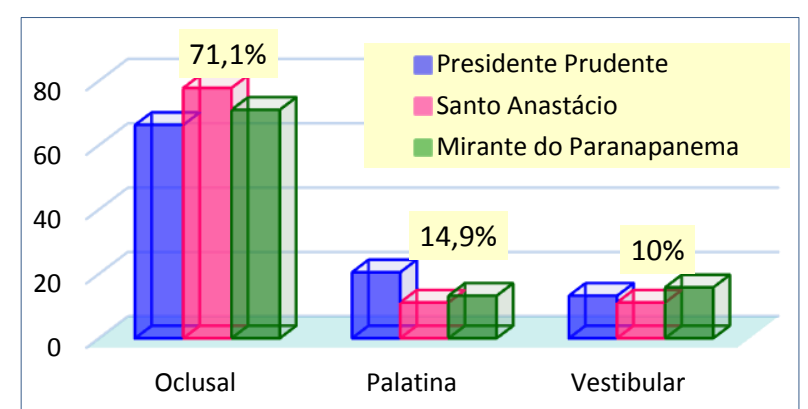

Figura 3: Distribuição percentual de acordo com a superfície dentária acometida.

\section{- Distribuição na superfície}

A Figura 4 mostra a distribuição do número e da porcentagem dos dentes de acordo com o padrão de distribuição na superfície dentária. Notou-se que na escola de Presidente Prudente, $80 \%$ dos dentes foram distribuídos parcialmente e $20 \%$ totalmente, não havendo dentes que apresentaram pontos separados (0\%), na escola de Santo Anastácio observou-se maior índice de distribuição em pontos separados $(78,3 \%)$, distribuição parcial $(17,4 \%)$ e total $(1,3 \%)$. Na escola de Mirante do Paranapanema, observou-se existência de dentes com distribuição maior em pontos separados (50\%), distribuição parcial $(42,3 \%)$ e total $(7,7 \%)$.

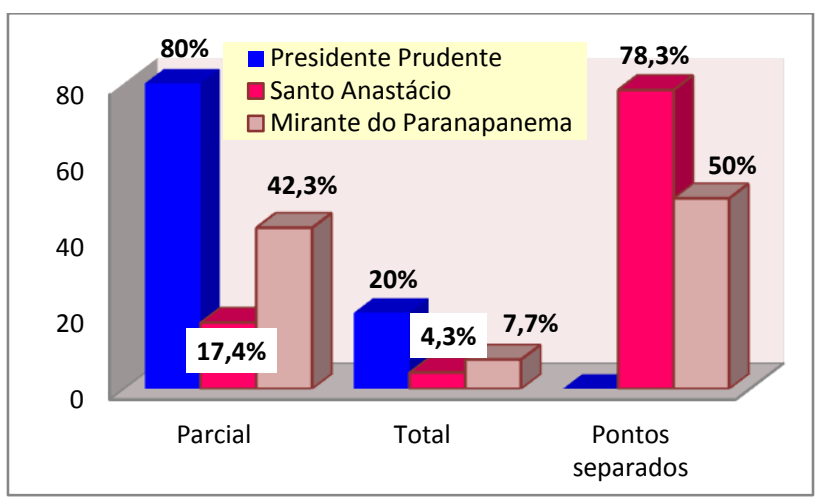

Figura 4: Distribuição percentual de acordo com a superfície dentária acometida.

- Cor

A Figura 5 mostra a distribuição do número e porcentagem dos dentes de acordo com a cor da pigmentação dos sulcos e fissuras, sendo utilizado o teste de Spearman para análise das variáveis. Observou-se que a cor preta foi a maior acometida na escola de Santo Anastácio (64\%) e a cor marrom foi a mais acometida nas escolas de Presidente Prudente $(55,2 \%)$ e Mirante do Paranapanema (51,7\%). Com as bactérias encontradas, não houve correlação positiva $(\mathrm{p}>0,05)$.

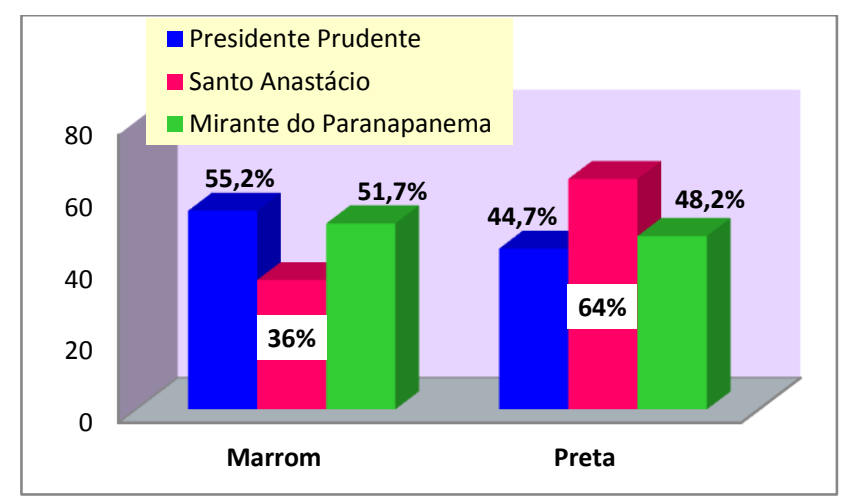

Figura 5: Distribuição do número e porcentagem dos dentes de acordo com a cor da pigmentação dos sulcos e fissuras.

\section{- Cavitação}

A Figura 6 apresenta os dados quanto ao número e a porcentagem da presença de cavitação. Notou-se que não houve presença de cavitação na maioria das crianças matriculadas nas 3 escolas. Havendo presença de cavitação apenas nas escolas de Presidente Prudente $(2,3 \%)$ e na de Mirante do Paranapanema (3,5\%).

\section{- Textura}

A distribuição do número e porcentagem dos dentes de acordo com a textura encontrada durante o exame tátil pode ser observada na Figura 7. Pode-se observar que a textura dura foi a mais encontrada nas 3 escolas, havendo textura amolecida apenas na escola de Presidente Prudente (7\%). 


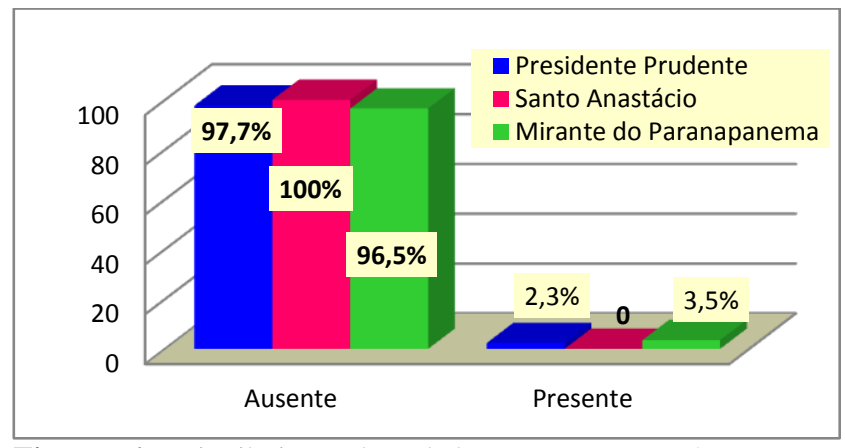

Figura 6: Distribuição dos dados quanto ao número e a porcentagem da presença de cavitação.

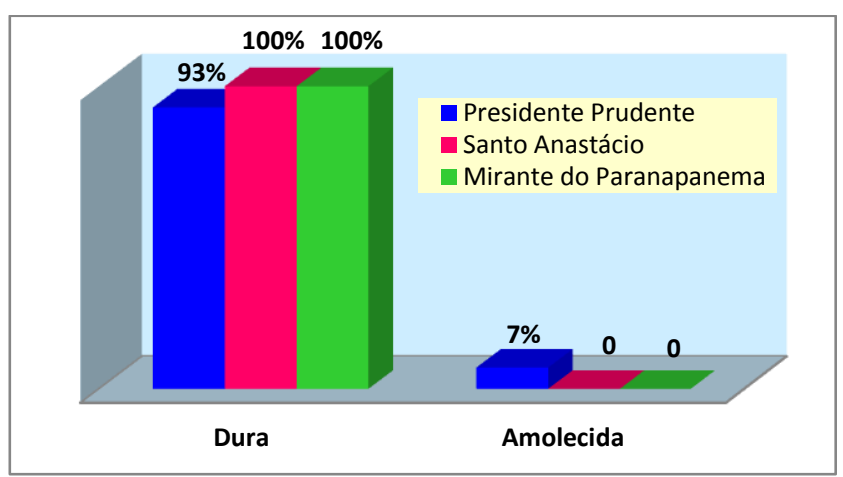

Figura 7: Distribuição do número e porcentagem dos dentes de acordo com a textura encontrada durante o exame tátil.

- Perfil microbiológico da pigmentação dentária dos sulcos e fissuras

A Figura 8 apresenta os microorganismos mais encontrados durante a avaliação microbiológica.

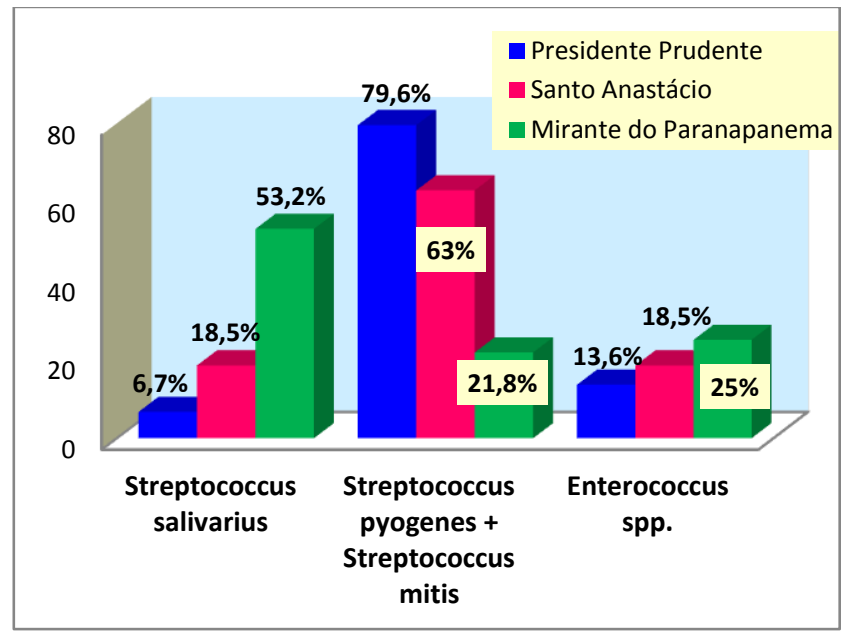

Figura 8: Distribuição do número e porcentagem dos dentes de acordo com a textura encontrada durante o exame tátil.

Foi observado que o S. pyogenes e S.mitis foram os microorganismos mais encontrados na escola de Presidente Prudente $(79,6 \%)$, seguido do Enteroccus spp. $(13,6 \%)$ e S. salivarius $(6,7 \%)$. Na escola de Santo Anastácio, notamos que o S. pyogenes e $\mathrm{S}$. mitis também foram os mais encontrados (63\%) e ambos Enteroccus spp. e S. salivarius tiveram a mesma aparição $(18,5 \%)$. Já na escola de Mirante do Paranapanema, observamos que o S. salivarius foi o mais encontrado $(53,2 \%)$, seguido do Enterococcus spp (25\%) e S. pyogenes e
S. mitis (21,5\%). Contudo, não foram encontradas diferenças estatísticas entre os mesmos ( $p>0,05)$, sendo utilizado o teste do qui-quadrado para análise.

\section{DISCUSSÃO}

Enterococcus são bactérias de flora normal intestinal, consideramos, portanto, um contaminante, estando em menor quantidade que os outros tipos bacterianos encontrados no trabalho. Mirante do Paranapanema apresentou maior nível de contaminação, seguido por Santo Anastácio e Presidente Prudente. Observamos que Presidente Prudente obteve maior nível de contaminação por S. pyogenes, considerando a condição climática do período em que se fora coletado e quantidade de crianças. Observamos que Mirante do Paranapanema, obteve a maior quantidade de Enterococcus spp., sugerindo contaminação por falta de higienização das mãos, que possivelmente foi levada à boca.

Estudos mostraram que os colonizadores de superfícies recentemente limpas constituem uma parte seleta de microflora oral, principalmente $\mathrm{S}$. sanguinis, S. oralis, S. mitis ${ }^{14}$. Essas observações implicam que a vasta maioridade dos colonizadores primários pertence ao 'grupo mitis'. A espécie predominante na superfície madura de placa pertence ao Actinomyces e Streptococcus, as quais a maioria é não-mutans ${ }^{22}$, comparado ao que foi encontrado no presente estudo. A maioria dos não-mutans, possuem $\operatorname{adesinas}^{23,24}$ as quais aderem às proteínas e aos açucares das películas adquiridas que revestem a superfície do dente. Esta parece ser uma das razões da dominância de não-mutans presentes no estágio inicial de formação da placa.

No geral, $69 \%$ das lesões envolvendo os molares, $52 \%$ envolvem a arcada inferior 25 , estando de acordo com o presente estudo, já que o mesmo, obteve $86,2 \%$ de acometimendo apenas em dentes inferiores.

Carvalho et al. ${ }^{7}$ relataram que os dentes com maior tendência à cárie são os recém irrompidos $\mathrm{e}$ fora de oclusão, discordando do que foi encontrado neste trabalho, onde o maior valor de referência quanto a idade é encontrada em crianças de 9 anos, onde o primeiro molar permanente já se encontra em oclusão.

No presente trabalho, as faces mais acometidas foram a face oclusal de primeiros molares permanentes inferiores $(21 \%)$, seguida da palatina dos primeiros molares superiores $(8 \%) 26$, o que fora encontrado neste estudo. Os primeiros molares inferiores foram os mais afetados no estudo de Botelho et al. ${ }^{27}$, visto que no presente estudo foi encontrado que os dentes 36 e 46 foram os mais acometidos, não possuindo diferença entre os mesmos.

Streptococcus pyogenes é a bactéria causadora de tonsilite, faringite, otite, impetigo, febre 
escarlatina, celulite e fasciíte necrosante ${ }^{28}$, o que sugere uma relação da presença da bactéria na cavidade oral durante o acometimento de cada uma dessas inflamações, no entanto, o S. pyogenes é de flora normal no organismo, não podendo ser considerado como fator causal. Podemos relacionar o S. pyogenes com o padrão de acometimento maior na arcada inferior, pela proximidade da faringe.

Poucos estudos examinaram extensivamente a microflora associada com dentes em erupção, embora haja evidências do aumento dos organismos potencialmente cariogênicos no tempo de erupção ${ }^{29}$, os resultados encontrados mostram que os indivíduos em tempo de erupção não apresentaram altos índices de cárie.

A detecção de S. mutans, ocorre em crianças com e sem cárie observável e foi relatado por ser o responsável pela criação de nichos retentivos para colonização de Lactobacillos, e outras bactérias envolvidas na doença ${ }^{30,31}$ como o que fora achado no estudo, bactérias como S. pyogenes, S. mitis e S. salivarius.

A progressão da cárie em esmalte é baseada numa lesão triangular nos cortes que passam pela porção central. A dissolução cariosa segue a direção dos prismas. Convencionalmente, a alta incidência de cárie nas superfícies oclusais, tem estado relacionada diretamente aos sulcos e fissuras estreitos e inacessíveis. Iniciação, propagação e progresso da lesão proximal representam um simples reflexo do ambiente específico criado pelas comunidades microbianas (biofilme) na superfície de esmalte no espaço proximal ${ }^{32}$.

Grande parte da preocupação científica e clínica relacionada à cárie oclusal tem sido dedicada aos possíveis eventos que ocorrem nas fissuras profundas e inacessíveis. Entretanto, a destruição cariosa quase sempre se inicia nas aberturas em função das atividades metabólicas dos acúmulos bacterianos superficiais ${ }^{32}$.

Já as cáries em dentina consistem na esclerose do túbulo dentinário, seguido pela desmineralização da dentina intertubular e destruição do túbulo, promovendo penetração bacteriana primeiramente nos túbulos dentinários e seguido por destruição da dentina intertubular ${ }^{33}$. No presente estudo, foram encontrados sulcos pigmentados, com a possibilidade de evolução para cavidades, com acúmulo de biofilme persistente, devido a falta de higiene, por bactérias não mutans, visto que são colonizadores iniciais de placa.

Em termos gerais, a cárie oclusal tem inicio nos locais onde as acumulações bacterianas são bem mais protegidas contra o desgaste funcional. Assim, dois fatores são considerados de importância para acumulo de placa e inicio de cárie: fase de erupção e anatomia específica ${ }^{32}$. Como foi visto no presente trabalho, onde a anatomia específica do dente (molares permanentes) induziu o acumulo de placa e deu início a lesão cariosa, estando no presente momento inativo. Quanto ao tempo de erupção foram obtidos dados que discordam já que, o maior índice de lesões cariosas foi encontrado em crianças onde os molares já se encontravam em função.

No estudo de Paula et al., os S. mutans foi correlacionado com fatores causadores da doença cárie $^{34}$, principalmente com $\mathrm{o}$ consumo de carboidratos fermentáveis, principalmente a sacarose ${ }^{35-38}$, no entanto, nesta pesquisa não foi encontrada correlação entre os fatores. Não foi encontrada associação entre dieta e condição dos microorganismos, sendo encontrada correlação com estação na época da coleta.

A fim de prevenir e controlar a cárie dentária nas superfícies oclusais, vários programas de prevenção têm sido realizados. No estudo de Moreira et. Al, foi-se utilizado uma técnica direcionada à higienização do primeiro molar permanente, e orientação de escovação convencional sendo observado redução na presença de placa estagnada por meio de técnicas não invasivas39. Com isso, campanhas enfatizando métodos e instrumentos de higiene para primeiros molares permanentes constituem uma necessidade.

Como foi analisado no trabalho, o diagnóstico precoce é essencial na progressão da cárie dentária, visto que podemos paralisar a lesão na "fase de sulcos pigmentados", impedindo sua progressão a partir de orientações quanto a higiene oral (técnicas adequadas para cada faixa etária, dentrifício fluoretado e escova dental apropriada), de dieta, consultas periódicas de retorno.

Quanto à prevenção, é de suma importância que seja realizada, visto que podemos prevenir que a lesão cariosa se forme, não permitindo que o biofilme se acumule.

CONCLUSÃO

Com base nos resultados obtidos e na metodologia empregada no presente trabalho, os microorganismos mais prevalentes foram $\mathrm{o}$ Enterococcus ssp, já os primeiros molares permanentes inferiores foram os dentes mais acometidos. Uma vez que a colonização bacteriana do sulco e a experiência de cárie podem ser afetadas pela idade, morfologia dentária, sequência eruptiva, variáveis relacionadas a dieta e fatores comportamentais e outros fatores possíveis contraditórios, outros estudos são necessários para estabelecimento.

\section{REFERÊNCIAS}

1. Brasil. Ministério da Saúde. Secretaria de Atenção à Saúde. Secretaria de Vigilância em Saúde. SB Brasil 2010: Pesquisa Nacional de Saúde Bucal: resultados principais Brasília: Ministério da Saúde; 2012. 
2. Sheiham A. Sucrose and dental caries. Nutr Health. 1987;5(1-2):25-9.

3. Sheiham A, James WPT. Diet and dental caries: the pivotal role of free sugars reemphasized. J Dent Res. 2015;94(10):1341-47.

4. Takahashi N, Nyvad B. Caries ecology revisited: microbial dynamics and the caries process. Caries Res. 2008;42(6):409-18.

5. Zenkner JEA, Alves LS, de Oliveira RS, Bica RH, Wagner MB, Maltz M. Influence of eruption stage and biofilm accumulation on occlusal caries in permanent molars: a generalized estimating equations logistic approach. Caries Res 2013;47(3):177-82.

6. Carvalho JC, Ekstrand KR, Thylstrup A. Dental plaque and caries on occlusal surfaces of first permanent molars in relation to stage of eruption. J Dent Res. 1989;68(5):773-79.

7. Carvalho JC. Caries process on occlusal surfaces evolving evidence and understanding. Caries Res 2014;48(4):339-46.

8. Poorterman JH, Weerheijm KL, Groen HJ, Kalsbeek H. Clinical and radiographic judgement of occlusal caries in adolescents. Eur J Oral Sci 2000;108(2):93-8.

9. Carvalho JC, Van Nieuwenhuysen JP, Maltz M. Traitement non-opératoire de la carie dentaire. Real Clin. 2004; 15(3):235-48.

10. Bertella N, Moura dos S, Alves LS, DaméTeixeira N, Fontanella V, Maltz M. Clinical and radiographic diagnosis of underlying dark shadow from drvalhoentin (ICDAS 4) in permanent molars. Caries Res 2013;47(5):429-32.

11.Ismail AI, Sohn W, Tellez M, Amaya A, Sen A, Hasson $\mathrm{H}$ et al. The International Caries Detection and Assessment System (ICDAS): an integrated system for measuring dental caries. Community Dent Oral Epidemiol. 2007;35(3):170-78.

12.Souza-Zaroni WC, Ciccone JC, Souza-Gabriel AE, Ramos RP, Corona SAM, Palma-Dibb RG. Validity and reproducibility of different combinations of methods for occlusal caries detection: an in vitro comparision. Caries Res. 2006;40(3):194-201.

13. Honkala S, ElSalhy M, Shyama M, Al-Mutawa SA, Boodai H, Honkala E. Sealant versus fluoride in primary molars of kindergarten children regularly receiving fluoride varnish: one-year randomized clinical trial follow-up. Caries Res. 2015;49(4):458-66.

14. Nyvad B, Killian M. Microbiology of the early colonization of human enamel and root surfaces in vivo. Scand J Dent Res. 1987;95(5):369-80.

15. Okada M, Soda Y, Hayashi F, Doi T, Suzuki J, Miura K et al. Longitudinal study of dental caries incidence associated with Streptococcus mutans and Strepcoccus sobrinus in pre-school children. J Med Microbiol. 2005;54(Pt7):661-65.
16.Loesche WJ. Role of Streptococcus mutans in human dental decay. Microbiol Rev. 1986; 50(4):353-80.

17.Carlsson P, Gandour IA, Olsson B, Rickardsson B, Abbas K. High prevalence of mutans streptococci in a population with extremely low prevalence of dental caries. Oral Microbiol Immunol. 1987;2(3):121-24.

18.Fujiwara T, Sasada E, Mima N, Ooshima T. Caries prevalence and salivary mutans streptococci in 0-2-years-old children of Japan. Community Dent Oral Epidemiol. 1991;19(3):151-54.

19. Hirose H, Hirose K, Isogai E, Miura H, Ueda I. Close association between Streptococcus sobrinus in the saliva of young children and smoothsurface caries increment. Caries Res 1993; 27(4):292-97.

20.Takahashi, K. Avaliação da microbiota bucal de mães e pares de crianças aos $6,12,18,24$ meses de idade e sua relação com a dieta alimentar, hábitos de higiene bucal, condição gengival, erupção dentária e prevalência de cárie dentária [tese]. Araçatuba: Universidade Paulista "Júlio de Mesquita Filho" Faculdade de Odontologia de Araçatuba; 2009.

21.Silva, JZ. Aspectos clínico, radiográfico e microbiológico da pigmentação em molares decíduos sob monitoramento preventivo. Estudo longitudinal [tese]. Araçatuba: Universidade Paulista "Júlio de Mesquita Filho" Faculdade de Odontologia de Araçatuba; 2009.

22.Ximénes-Fyvie LA, Haffajee AD, Socransky SS. Microbial composital of supra- and subgingival plaque in subjects with adult periodontitis. J Clin Periodontol. 2000;27(2):722-32

23. Gibbons RJ. Bacterial adhesion to oral tissues: a model for infectious diseases. J Dent Res. 1989;68(5):750-60.

24.Kolenbrander PE. Oral microbial communities: biofilms, interactions, and genetic systems. Annu Rev Microbiol. 2000;54:413-37.

25.Makhija SK, Gilbert GH, Funkhouser E, Bader JD, Gordan VV, Rindal DB et al. Characteristics, detection methods and treatment of questionable occlusal carious lesions: findings from The National Dental Practice-Based Research Network. Caries Res 2014;48(3):200-7

26. Thibodeau EA, O'Sullivan DM. Salivary mutans streptococci and caries development in the primary and mixed dentitions of children. Community Dent Oral Epidemiol. 1999; 27(6):406-12.

27. Botelho K, Carvalho L, Maciel R, Franca C, Colares V. Clinical aspects of first permanente molars - in children between 6 and 8 years old. Odontol Clin Cient. 2011;10(2):167-71.

28.Maddocks SE, Wright CJ, Nobbs AH, Brittan JL, 
Franklin L, Strömberg N et al. Streptococcus pyogenes antigen I/II-family polypeptide AspA shows differential ligand-binding properties and mediates biofilm formation. Mol Microbiol. 2011; 81(4):1034-49.

29. Meurman JH, Rytomaa I, Murtomaa H, Turtola L. Erupting thid molars and salivary lactobacilli and Streptococcus mutans counts. Scand J Dent Res 1987;95(1):32-6.

30.Caufield PW, Li Y, Bromage TG. Hypoplasiaassociated severe early childhood caries - a proposed definition. J Dent Res. 2012;91(6):544-50.

31.Caufield PW, Schön CN, Saraithong P, Li Y, Argimón S. Oral lactobacili and dental caries: a model for niche adaptation in humans. J Dent Res. 2015;94(9 Suppl):110S-8S.

32.Fejerskov O, Nyvad B, Kidd E. Cáries Dentárias A doença e seu tratamento clínico. In: Fejerskov O. Patologia da cárie dentária. Rio de Janeiro: Santos; 2017. p. 44-59.

33. Frank RM. Structural events in the caries process in enamel, cementum, and dentin. J Dent Res. 1990;69(Spec):559-66,634-36.

34.Burt BA, Pai S. Sugar consumption and caries risk: a systematic review. J Dent Educ. 2001; 65(10):1017-23.

35.Sgan-cohen HD, Newbrun E, Huber R, Tenebaum $\mathrm{G}$, Sela MN. The effect of previous diet on plaque $\mathrm{pH}$ response to different foods. J Dent Res. 1988;67(11):1434-37.

36. Yang Y, Sreenivasan PK, Subramanyam R, Cummins D. Multiparameter assessments to determine the effects of sugars and antimicrobials on a polymicrobial oral biofilm. Appl Environ Microbiol. 2006;72(10):6734-42.

37. Weiss RL, Trithart AH. Between-meal eating habits and dental caries experience in preschool children. Am J Public Health Nations Health. 1960;50(8):1097-1104.

38. Filoche SK, Soma KJ, Sissons CH. Caries-related plaque microcosm biofilms developed in microplates. Oral Microbiol Immunol. 2007;22(2):73-9.

39. Moreira KMS, Vargas AMD, Normando D, Ferreira EF. Plaque control in the first permanent molar: cost/benefit analysis. Arq Odontol 2016;52(2):64-9.

\section{CONFLITO DE INTERESSES}

Os autores declaram não haver conflitos de interesse.

\section{AUTOR PARA CORRESPONDENCIA}

\section{Karine Takahashi}

karine@unoeste.br
Submetido em 18/09/2018

Aceito em 12/03/2019 